\title{
A Compreensão de Licenciandos em Matemática sobre o Ensino via Resolução de Problemas: análise por meio de uma proposta de formação
}

\author{
Marcelo Carlos de Proença \\ Professor, Universidade Estadual de Maringá \\ Departamento de Matemática \\ mcproenca@uem.br
}

\begin{abstract}
Resumo
O objetivo foi o de investigar a compreensão de licenciandos em Matemática sobre a abordagem da resolução de problemas no ensino, especificamente voltado à compreensão do uso do problema como ponto de partida e com base nas várias estratégias de resolução. Quatro licenciandos em Matemática, estudantes de uma universidade pública, participaram de um curso sobre resolução de problemas. Os resultados mostraram que os participantes fizeram maior uso de estratégias, envolvendo equação. A estratégia de encontrar um padrão foi a mais difícil e precisaria ser conduzida pelo professor em sala de aula na escola. Também passaram a visualizar e utilizar diferentes estratégias de resolução. Consideramos que os futuros professores puderam compreender que no ensino via resolução de problemas há a necessidade de uma previsão das possíveis estratégias de resolução, tendo em vista ações no ensino para favorecer uma articulação das estratégias dos alunos ao conteúdo.
\end{abstract}

Palavras-chave: Licenciatura em Matemática. Resolução de Problemas. Estratégias.

\section{The Understanding of Undergraduates in Mathematics on Teaching via Problem Solving: analysis through a training proposal}

\begin{abstract}
The aim was to investigate the understanding of undergraduates in mathematics on the approach to problem solving in teaching specifically aimed at understanding the problem of using as a starting point and based on various solving strategies. Four undergraduates in mathematics, students at a public university, attended a course on problem solving. The results showed that participants made greater use of strategies involving equation. The strategy of finding a pattern was the most difficult and would need to be conducted by the teacher in the classroom at school. Also came to view and use different solving strategies. We believe that future teachers could understand that teaching via problem solving there is a need for an estimate of possible resolution strategies, considering actions in education to favor a articulation strategies of the students to the content.
\end{abstract}

Keywords: Degree in Mathematics. Problem Solving. Strategies. 


\section{Introdução}

O presente estudo decorre de nossa investigação de doutorado ${ }^{1}$, referente à formação do futuro professor de Matemática, envolvendo a temática da resolução de problemas. Diante disso, nas Diretrizes Curriculares Nacionais para a Formação de Professores da Educação Básica (Parecer CNE/CP 9/2001, BRASIL, 2002) consta que a orientação à formação do professor para a atividade docente deve, entre outras coisas, favorecer o desenvolvimento de competências necessárias à atuação do professor, entre elas as competências referentes ao domínio pedagógico.

Sobre o aspecto referente ao domínio pedagógico, na visão de Shulman (1986), é necessário conhecimento pedagógico do conteúdo, ou seja, conhecimento de formas de ensino que favoreçam a aprendizagem. No caso do presente estudo, focamos o conhecimento sobre a abordagem da resolução de problemas ao ensino de conteúdos de Matemática. Porém, essa abordagem parece não ser trabalhada de forma coerente em sala de aula. Pesquisas realizadas sobre a temática têm mostrado que professores que lecionam nas escolas de Educação Básica exercem um ensino ou tem conhecimento que corresponderia à introdução de conceitos formais para depois abordar problemas (REDLING, 2011; PROENÇA, 2014).

Na visão de Schroeder e Lester (1989), uma condução de ensino coerente seria a de se abordar, justamente, o problema como ponto de partida. Para esses autores, nessa abordagem, é possível levar os alunos a articularem seus conhecimentos prévios de Matemática na busca de estratégias de resolução, desenvolvendo a compreensão de conceitos e procedimentos matemáticos.

Possivelmente, essas dificuldades de professores da escola em conduzir aulas baseadas na resolução de problemas, não adotando o problema como ponto de partida, podem estar relacionadas às dificuldades advindas dos cursos de Licenciatura em Matemática.

A pesquisa de Pirola et al. (2006) mostrou que licenciandos em Matemática apresentavam dificuldades para perceber no enunciado dos problemas propostos as informações completas, bem como as informações incompletas e supérfluas. No estudo de Leite et al. (2012), estudantes do quarto e oitavo semestres do curso de Licenciatura em Matemática apresentaram dificuldades conceituais nos assuntos de função e de geometria do ensino básico, bem como dificuldades na leitura e interpretação dos problemas trabalhados.

Em termos do uso do problema no ensino, a pesquisa de Proença (2013) mostrou que os quatro participantes da pesquisa, alunos do quarto ano do curso de Licenciatura em Matemática, apresentaram um entendimento da abordagem da resolução de problemas como aquela em que primeiro se apresentam as definições e regras matemáticas para somente depois tratar de problemas.

\footnotetext{
${ }^{1}$ Pesquisa desenvolvida com apoio financeiro da Capes.
} 
Esses estudantes relataram que o trabalho sobre a resolução de problemas no curso ficou apenas em nível da discussão sobre sua importância no ensino.

Nesse sentido, percebe-se que os futuros professores de Matemática estão terminando o curso e com pouco conhecimento sobre a resolução de problemas no ensino. Assim, visando a uma formação que elucide e gere reflexões sobre a abordagem da resolução de problemas em sala de aula, nosso objetivo neste estudo foi o de favorecer e analisar a compreensão de licenciandos em Matemática sobre a abordagem do problema como ponto de partida no ensino, tomando como base uma discussão das estratégias de resolução.

\section{A resolução de problemas no ensino de Matemática}

A respeito do significado do termo problema, Chi e Glaser (1992, p. 251) definiram que "um problema é uma situação na qual você está tentando alcançar algum objetivo e deve encontrar um meio de chegar lá." Assim, Brito (2006), ao analisar as ideias de alguns autores, apontou que o processo de resolução de problemas segue, em síntese, as seguintes fases/etapas: representação, planejamento, execução e monitoramento.

Na etapa de representação, tem-se que a pessoa deve fazer uma representação mental do problema, consistindo "[...] essencialmente da interpretação ou compreensão do problema por aquele que o soluciona" (CHI; GLASER, 1992, p. 255). Na etapa de planejamento, a pessoa deve propor/elaborar uma estratégia de resolução com base na compreensão que teve do problema. Na etapa de execução, deve-se desenvolver a estratégia, efetuando os cálculos, operações, realizando os desenhos de forma correta etc. Por fim, a etapa de monitoramento implica na análise do processo seguido, analisando a racionalidade da resposta encontrada.

A respeito do aspecto do uso de estratégias de resolução, Cai e Lester (2012), baseados em pesquisas, apresentaram orientações ao ensino da resolução de problemas e apontaram, entre outras coisas, a importância de os alunos serem envolvidos na busca de múltiplas estratégias de resolução de um dado problema. Assim, no ensino, algumas estratégias que poderiam ser utilizadas seriam as seguintes: reconhecer padrões (generalização, obtida por meio do uso de casos particulares), trabalhar no sentido inverso, supor e testar, simulação e experimentação, redução, listagem exaustiva, dedução lógica e representação de dados (gráfico, equação, expressão algébrica, tabela (ou quadro), lista, diagrama) (KRULIK; RUDNICK, 1982).

Diante disso, Krulik e Rudnick (1982) destacaram que o ensino baseado na resolução de problemas não corresponde à ideia de ensinar algoritmos específicos para resolver problemas.

Como um processo, resolução de problemas é o significado pelo qual um indivíduo usa conhecimento e entendimento adquiridos previamente para satisfazer as demandas de uma situação não familiar. O estudante deve sintetizar o que ele ou 
ela aprendeu e aplicar em novas e diferentes situações. (KRULIK; RUDNICK, 1982, p. 42).

Tendo em vista o que seria um problema e o processo de resolução de problemas, Schroeder e Lester (1989) apresentaram a abordagem de ensinar via resolução de problemas como uma ação coerente no ensino, pois implicaria no ensino de um tópico de Matemática, iniciando-se por meio de uma situação-problema. Segundo esses autores, trata-se de uma articulação entre um problema do mundo real a uma forma abstrata que envolveria simbologia matemática e técnicas específicas para operar com essa simbologia.

Outras duas abordagens apontadas por esses autores, ensinar sobre resolução de problemas e ensinar para resolução de problemas, seriam duas formas limitantes de se abordar o conteúdo de Matemática. Na primeira, é feita uma discussão explícita de como problemas são resolvidos, o que corresponderia a apresentar fases de resolução, como as de George Polya, para que os alunos a utilizem ao resolver os problemas. Em nossa opinião, trata-se de uma forma linear e equivocada de trabalho baseado na resolução de problemas, pois um aluno que tenha uma compreensão inadequada do problema, possivelmente não conseguirá resolvê-lo.

No caso da segunda abordagem, o limite seria ainda maior no sentido de que a "resolução de problemas é vista como uma atividade em que os alunos somente se engajam depois da introdução de um novo conceito ou para seguir uma habilidade de cálculo ou um algoritmo" (SCHROEDER; LESTER, 1989, p. 34, grifo dos autores).

Destaca-se que nos documentos Parâmetros Curriculares Nacionais de Matemática - PCN (BRASIL, 1998) indica-se um trabalho por meio da resolução de problemas, sendo que o problema deve ser o ponto de partida na introdução dos conteúdos/conceitos e não as definições e/ou fórmulas.

Assim, no que se refere a ações a serem desenvolvidas em sala de aula, a introdução de uma situação de Matemática (problema como ponto de partida) implicaria em apresentar, na visão de Bittar e Freitas (2005), problemas interessantes e criativos que busquem justamente a motivação dos alunos para tentar resolvê-los.

Isso indica que os alunos devem ser levados a compreender que se trata de uma situação problemática na qual se tem que pensar e não como algo que se deve seguir uma condição prescritiva (FI; DEGNER, 2012). Uma forma de fazer com que os alunos avaliem suas formas de pensamento seria o de propor problemas em que se admitam vários caminhos de resolução, bem como que existam várias soluções possíveis (POZO; ANGÓN, 1998).

Além disso, os alunos precisam de tempo para resolver as situações propostas, cabendo ao professor verificar o nível em que os alunos realizam um planejamento prévio, uma reflexão e 
autoavaliação sobre o processo de resolução. Nesse caso, a avaliação da aprendizagem deve focar sobre os processos e não somente sobre a resposta encontrada (POZO; ANGÓN, 1998).

Ao final, deve (deveria) ocorrer uma discussão das estratégias dos alunos, momento em que Charles (1985) indicou que se deve solicitá-los a explicitarem suas estratégias de resolução verbalmente ou em lousa. Nesse momento, é importante solicitar que eles verifiquem o problema abordado e a racionalidade da resposta encontrada. Assim, podem-se focar os conceitos errôneos e os raciocínios utilizados pelos alunos, bem como uma atitude de responsabilidade, perante a resolução do problema (FI; DEGNER, 2012).

Proença (2015) realizou uma pesquisa que buscou favorecer a compreensão sobre o ensino de frações via resolução de problemas a futuras professoras de pedagogia. Nesse estudo, as categorias elaboradas para análise foram indicadas pelo pesquisador como ações de referência no ensino dos conteúdos/conceitos de Matemática em que se adota o problema como ponto de partida, a saber:

Problema como ponto de partida: referente à indicação do problema como ponto de partida para introduzir o tópico/assunto [...];

Permitir aos alunos expor suas estratégias: referente a possibilitar aos alunos a resolverem, sozinhos, o problema, expondo, assim, suas estratégias de resolução. Desse modo, o objetivo é o de evitar a apresentação direta de algoritmos específicos;

Discutir as estratégias dos alunos: corresponde a proporcionar uma discussão das estratégias/caminhos de resolução dos alunos, o que, de modo geral, leva em consideração avaliar como desenvolveram as etapas do processo de resolução;

Articular as estratégias dos alunos ao conteúdo: implica no uso das estratégias dos alunos como base para articular ao novo conteúdo [...], favorecendo, assim, sua compreensão. (PROENÇA, 2015, p. 745, grifos do autor).

Assim, a condução do ensino via resolução de problemas por meio dessas ações, apontadas anteriormente, poderia ajudar o professor a desenvolver suas aulas e, assim, levar os alunos a compreender a Matemática.

\section{Metodologia}

Desenvolvemos um Curso sobre Resolução de Problemas que se constituiu em um contexto no qual tivemos como objetivo favorecer conhecimentos acerca do ensino via resolução de problemas. Os participantes foram quatro licenciandos do quarto ano do curso de Licenciatura em Matemática, período noturno, de uma universidade estadual pública do interior do Estado de São Paulo, denominados neste estudo de L1, L2, L3 e L4, sendo os dois primeiros do gênero feminino e os dois últimos, masculino.

As atividades do curso foram desenvolvidas no primeiro semestre de 2010, no período noturno, horário das aulas dos licenciandos, de periodicidade quinzenal. Teve duração de 30 horas, 
totalizando oito encontros, os quais foram gravados em vídeo para posterior transcrição dos diálogos e para retomada das estratégias discutidas e registradas em lousa.

Assim, a nossa investigação, na perspectiva de Bogdan e Biklen (1994), é de cunho qualitativo, tendo como fonte direta de dados o ambiente natural onde ocorrem as ações das pessoas (o contexto do Curso de Resolução de Problemas), constituindo o investigador o instrumento principal. Além disso, nossa preocupação foi pelo processo em que se dão as ações das pessoas do que simplesmente pelos resultados ou produtos (BOGDAN; BIKLEN, 1994).

O Quadro 1 mostra um resumo geral das atividades desenvolvidas no Curso sobre Resolução de Problemas. Como se pode observar, 10 horas foram destinadas para as atividades sobre aspectos teóricos da resolução de problemas, enquanto que 18 horas serviram para discutir as estratégias de resolução dos problemas feitas pelos participantes, bem como as apresentadas pelo pesquisador.

Quadro 1 - Resumo geral das atividades desenvolvidas no curso

\begin{tabular}{|c|c|c|}
\hline \multirow{2}{*}{ Encontros } & Horas-aula & Atividade desenvolvida \\
\hline \multirow{2}{*}{$1^{\circ}$} & 2 & Aspectos teóricos da resolução de problemas \\
\cline { 2 - 3 } & 2 & Resolução dos problemas propostos e discussão das estratégias \\
\hline $2^{\text {o }}$ & 4 & Resolução dos problemas propostos e discussão das estratégias \\
\hline $3^{\text {o }}$ & 4 & Resolução dos problemas propostos e discussão das estratégias \\
\hline $4^{\circ}$ & 4 & Aspectos teóricos da resolução de problemas \\
\hline $5^{\circ}$ & 4 & Aspectos teóricos da resolução de problemas \\
\hline $6^{\circ}$ & 4 & Resolução dos problemas propostos e discussão das estratégias \\
\hline $7^{\circ}$ & 4 & Resolução dos problemas propostos e discussão das estratégias \\
\hline $8^{\circ}$ & 2 & \\
\hline
\end{tabular}

Fonte: Elaborado pelo autor.

No caso das discussões dos aspectos teóricos, no primeiro encontro, discutimos a presença da resolução de problemas no currículo de Matemática. No quarto e quinto encontros, dialogamos e refletimos sobre características e aspectos importantes da resolução de problemas, a saber: (a) o que seria um problema, diferenciando-o dos conhecidos exercícios; (b) etapas de resolução de problemas; (c) a resolução de problemas no ensino e na aprendizagem da Matemática, evidenciando a importância da abordagem via resolução de problemas, a qual sugere utilizar o problema como ponto de partida na introdução de conteúdos/conceitos de Matemática. Além disso, tratamos das limitações oriundas das abordagens sobre e para resolução de problemas.

Nos encontros referentes à resolução dos problemas propostos e discussão das estratégias de resolução, foram resolvidas 28 situações de Matemática para uma compreensão do processo de resolução de problemas (etapas de resolução - compreensão, planejamento, execução e monitoramento) e se configuravam como problemas aos participantes. Buscamos, assim, evidenciar 
as estratégias de resolução desses participantes e apresentar as estratégias propostas pelo pesquisador: diagramas, tabela/quadro, encontrar um padrão, figuras/desenhos, supor e testar, lista, equação etc.

Antes de tratarmos das características da resolução de problemas e da abordagem do problema como ponto de partida no ensino de um conteúdo, realizamos, nos segundo e terceiro encontros, a resolução de 12 situações de Matemática. O objetivo dessa condução das aulas no Curso de Resolução de Problemas foi o de, primeiro, tratar e situar os futuros professores de Matemática na resolução dessas situações, tendo em vista a apreensão de um conhecimento inicial sobre as possíveis estratégias de resolução. Nesse período, discutimos, na perspectiva dos participantes, se o processo de resolução seguido por eles estava adequado.

Em seguida, nos quarto e quinto encontros, discutimos, por meio de leituras de textos selecionados e da apresentação de slides sobre os princípios teóricos da resolução de problemas (significados de problema e do processo de resolução de problemas), articulando-os a essas 12 situações que foram resolvidas. Depois, fizemos o mesmo tipo de discussão para tratar do ensino via resolução de problemas e das ações do professor em sala de aula para conduzir a abordagem do problema como ponto de partida até a articulação ao conteúdo. Nesse momento, os estudantes foram informados que o modo como estavam resolvendo as situações era justamente a forma como poderiam conduzi-las na sala de aula da escola.

Desse modo, a condução no curso da resolução das 28 situações de Matemática seguiu de forma semelhante às ações no ensino propostas por Proença (2015), nas quais primeiro se apresentou o problema. Depois se permitiu aos participantes tentarem resolver pelos seu próprios conhecimentos, solicitando-se que ficassem agrupados em duplas para discutirem a respeito das possíveis estratégias que os ajudariam a resolver as situações propostas. Em seguida foi feita uma discussão coletiva de suas estratégias, sendo que apenas a partir do problema sete os participantes se sentiram à vontade para vir até a lousa expor o que tinham feito. Destaca-se que, quando não conseguiam propor uma forma de resolução, o pesquisador conduzia uma já prevista para o curso, solicitando a participação deles para mencionar valores numéricos ou mesmo conceitos e procedimentos matemáticos para que, juntos, construíssemos a estratégia. Nesse momento, solicitou-se que apresentassem um nome para cada uma das estratégias, pois queríamos que houvesse uma delimitação acurada para lhes ampliar a compreensão. Por fim, buscamos articular as estratégias dos licenciandos e mesmo a do pesquisador ao conteúdo envolvido por meio da relação ou apresentação da forma matemática de resolução.

Nos sexto e sétimo encontros, discutimos a resolução da outra parte das situações de Matemática, a qual ficou para ser feita em casa. No sexto encontro, as situações de números 13 ao 
19 foram feitas com maior compreensão pelos participantes, tendo em vista a discussão anterior dos aspectos teóricos. Porém, no sétimo encontro, dos problemas 20 ao 28, os participantes apenas trouxeram resolvido o de número 20. Para alguns destes problemas, o pesquisador teve que mostrar uma estratégia. Para outros, esses estudantes conseguiram perceber/apontar o tipo de estratégia a ser utilizada, sendo desenvolvida em conjunto por eles e o pesquisador.

Assim, a nossa análise se deteve em dois eixos para uma discussão dos dados, a saber:

a) Das estratégias utilizadas: foi feita a apresentação de uma síntese dos tipos e da quantidade de estratégias, utilizadas pelos futuros professores. Buscamos analisar, também, as impressões dos participantes sobre duas estratégias que lhes foram apresentadas, pois nunca as tinham utilizadas: montar uma tabela e a de construir uma tabela e encontrar um padrão. Por fim, evidenciamos o motivo que os levou a não resolver algumas das situações de Matemática (problemas 21 ao 28).

b) Da compreensão do ensino via resolução de problemas: evidenciamos a compreensão dos futuros professores sobre o ensino via resolução de problemas por meio da descrição e análise dos diálogos estabelecidos entre os participantes e o pesquisador a respeito da situação de Matemática de número 14, tendo por base as possíveis estratégias que surgiram. Tal situação foi escolhida porque, após às discussões dos aspectos teóricos sobre a resolução de problemas, foi o primeiro problema (e o único) em que os participantes manifestaram a compreensão da abordagem do problema como ponto de partida, tendo em vista as possíveis estratégias que poderiam ser utilizadas. Essa escolha também se deu porque evidenciaram, de forma geral, a percepção de se conduzir aulas na perspectiva de ensino proposta por Proença (2015).

\section{Análise e discussão das estratégias utilizadas}

No primeiro eixo de análise, Das estratégias utilizadas, a síntese dos tipos/quantidade das estratégias utilizadas pelos participantes evidenciou as seguintes: a) a de se estabelecer uma equação $(n=21)$; b) a do uso de equação e uma figura $(n=10)$; c) a do uso de tabela $(n=06)$; d) a do uso de uma P.A. $(\mathrm{n}=05)$; e) a do uso de tabela e de se encontrar um padrão $(\mathrm{n}=04) ; \mathrm{f})$ a da dedução lógica $(\mathrm{n}=03) ; \mathrm{g})$ a do uso de tabela e de diagrama $(\mathrm{n}=02) ; \mathrm{h})$ a do uso de figura $(\mathrm{n}=02)$; i) a do uso da fórmula da Combinação Simples $(n=02)$ j) a do uso de equação e tabela $(n=01) ; k)$ a do uso de tabela e de P.A. $(\mathrm{n}=01)$.

Duas estratégias apresentadas pelo pesquisador foram novidades para os participantes da pesquisa: a de montar uma tabela e a de construir uma tabela e encontrar um padrão. Apesar de ter sido apresentada no problema 1 e no problema 10, os estudantes L1 e L4 conseguiram utilizar a 
estratégia de se montar uma tabela no problema 11 (A mãe de Jesse pagou a mesada de 1 dólar e 60 centavos em moedas de 0,25, 0,10 e 0,05. Ele recebeu ao todo 17 moedas. Quantas moedas de cada valor a mãe lhe deu?).

Assim, mesmo L3 não ter conseguido fazer uso de uma tabela, mostrou gosto pelo entendimento que teve: Ai que legal! Nossa, não é que meio óbvio! Eu só enxerguei agora porque está feito. Mas quanto mais moedas de 25, mais a chance de... não vai dar muito, mas o 4 vai dar um (1 dólar)... o 5 vai dar 125 e o 6 vai dar... 150. Acabou! Aí já era! Para 6 já era e para 5 já mata, porque ainda vai faltar muita moeda.

Já sobre a estratégia apresentada pelo pesquisador para construir uma tabela e depois encontrar um padrão, foi trabalhada pela primeira vez no problema 12. Assim, L1, L2 e L3 tiveram a iniciativa de utilizá-la no problema 13 , mas precisaram da ajuda do pesquisador para compreender a construção primeira de uma tabela. O Quadro abaixo mostra o problema 13.

Quadro 2 - Situação de Matemática (problema 13) para discutir sobre encontrar um padrão

13. Um número que pode ser representado pelo padrão abaixo é chamado número triangular. Os quatro primeiros números são mostrados. Qual é o qüinquagésimo número triangular?

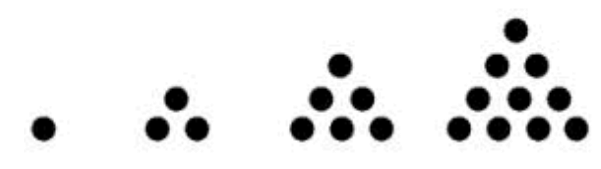

Fonte: Kantowski (1997).

Realmente essa estratégia parece ter sido a mais difícil para os participantes da nossa pesquisa, pois apenas L4 a utilizou novamente (problema 18), e não foi possível verificar se a utilizariam nos problemas finais que permitiam seu uso (27 e 28) porque não tentaram resolvê-los.

A pesquisa de Nunes (2010), tendo como objetivo favorecer a formação de licenciandos em Matemática à compreensão do Ensino-Aprendizagem-Avaliação da Matemática através da Resolução de Problemas, abordou, entre outros assuntos, a busca de padrões. Em uma atividade que envolvia encontrar um padrão ao número de abdominais e outro ao total de abdominais realizado por uma pessoa, os alunos recorreram às fórmulas do conteúdo de Progressão Aritmética (P.A.), sendo que a professora acabou tendo que mostrar como se dava a construção de uma tabela e, posteriormente, conduziu-lhes à busca dos padrões.

Em um diálogo entre L2 e L4 para saber se os alunos da escola conseguiriam utilizar essa estratégia de construção de tabela e encontrar um padrão, L4 respondeu: se ensinar eles aprendem, mas sozinhos eles não fazem. A pesquisa de Souza (2010), ao buscar favorecer a compreensão para encontrar/usar um padrão em problemas de Análise Combinatória a alunos do Ensino Médio, 
mostrou justamente essa necessidade de o professor conduzir o ensino dessa estratégia. Nessa pesquisa, apesar de esses alunos terem construído uma lista organizada de dados, representação dos dados por meio de um diagrama e mesmo a construção de uma tabela de dupla entrada, nenhum deles conseguiu estabelecer condições para obter um padrão, sendo que a professora acabou mostrando como isso poderia ser feito.

Por fim, a análise no eixo Das estratégias utilizadas mostrou que a partir do problema 21 nenhum dos participantes tentou resolver os problemas. Ele tiveram a tarefa de ter que resolvê-los em outro momento para posteriormente serem trazidos para discussão em sala de aula, mas isso não ocorreu. Nos problemas que envolviam construção geométrica com régua e compasso (22, 23 e 25), os participantes relataram que tinham dificuldades nesse assunto: Eu não sei fazer nada disso (L2); Eu não sei desenho geométrico (L4). Isso acabou revelando uma formação deficitária advinda do curso de Licenciatura: você quer que eu traga meu caderno de desenho de geometria? Ele deve dar umas 20 folhas o ano inteiro (L2).

Entende-se que as dificuldades desses futuros professores não seriam apenas em desenho geométrico, mas também no uso de conceitos de geometria, o que pode acarretar em uma má compreensão de problemas e, assim, na escolha/execução de uma estratégia equivocada. Apesar disso, o participante L4, no caso do problema 22, destacou o seu gosto pelo que foi feito: legal essa! Nós temos que pegar e ver coisas como essas de novo. Diante dessas estratégias utilizadas pelos participantes, passamos a discorrer sobre a análise de uma situação de Matemática específica.

\section{Análise e discussão da compreensão do ensino via resolução de problemas}

No último eixo, Da compreensão do ensino via resolução de problemas, analisamos a compreensão dos participantes da abordagem do problema como ponto de partida e da sua condução no ensino, tendo por base as estratégias de resolução, da seguinte situação de Matemática: Na escola de Tom há seis times de basquete. Eles querem planejar um torneio para após as aulas, de maneira que cada time jogue uma única vez com todos os outros. Quantas partidas devem ser jogadas?

Dois participantes apresentaram duas estratégias cada um, todas diferentes. O participante L4 utilizou "tabela/quadro" e "diagrama" (de flechas). O participante L1 utilizou uma figura com a fórmula das diagonais de polígonos (“figura e equação") e a fórmula de Combinação Simples. Naquele momento, o pesquisador pediu a L4 que descrevesse a estratégia de diagrama e a L1 que apresentasse as ideias da estratégia do uso da figura para que pudesse representá-las na lousa. A estratégia de L4 ficou assim: 


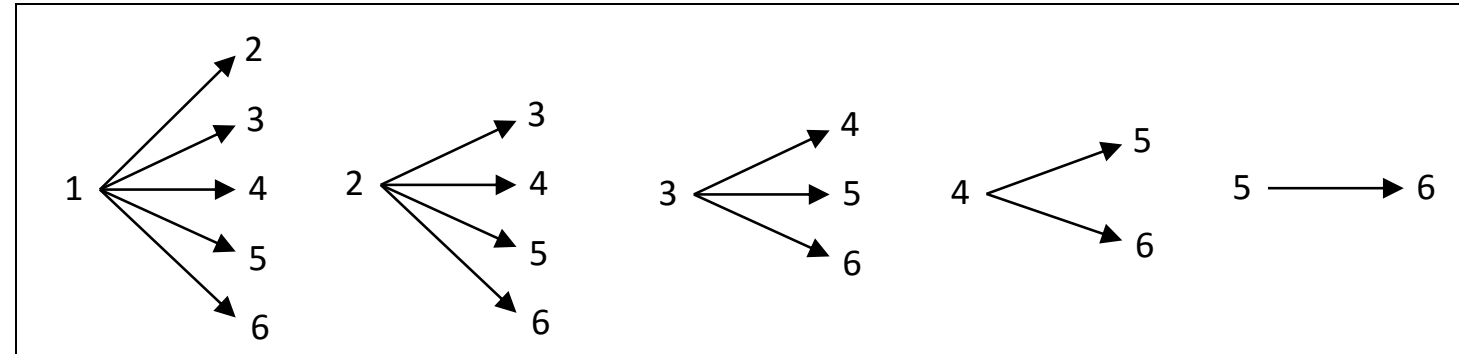

Resposta: Devem ser jogadas 15 partidas.

Fonte: Fragmento de pesquisa

A estratégia de L1 foi o de construir um desenho de um hexágono para contar as diagonais e depois somar os lados: cruzei as diagonais, só que aí eu contei mais os lados. No entanto, as diagonais foram obtidas pela fórmula do número de diagonais: daí eu usei a fórmula da diagonal e somei os lados. A fórmula é $n(n-3) / 2$. Dividido por $2 \ldots$ aí você não repete pares. Você pode ligar tudo. A resolução ficou assim:

Figura 2 - Estratégia de L1 baseada no uso de uma figura e equação

9 diagonais +6 lados $=15$ possibilidades
Resposta: Devem ser jogadas 15 partidas.

Fonte: Fragmento de pesquisa.

Nessas duas estratégias, verificamos que esses participantes já tinham uma percepção mais acurada do processo de resolução. Por exemplo, não apenas mostraram maior atenção à compreensão que tinham dos problemas, mas também passaram a apresentar uma resposta à pergunta contida no enunciado, atitude que lhes faltava quando da resolução das 12 primeiras situações de Matemática que foram resolvidas antes das discussões dos aspectos teóricos.

Em seguida, o pesquisador mostrou aos participantes uma estratégia utilizada por uma criança nessa situação de Matemática (Figura 3). 
Figura 3 - Estratégia de resolução de uma criança

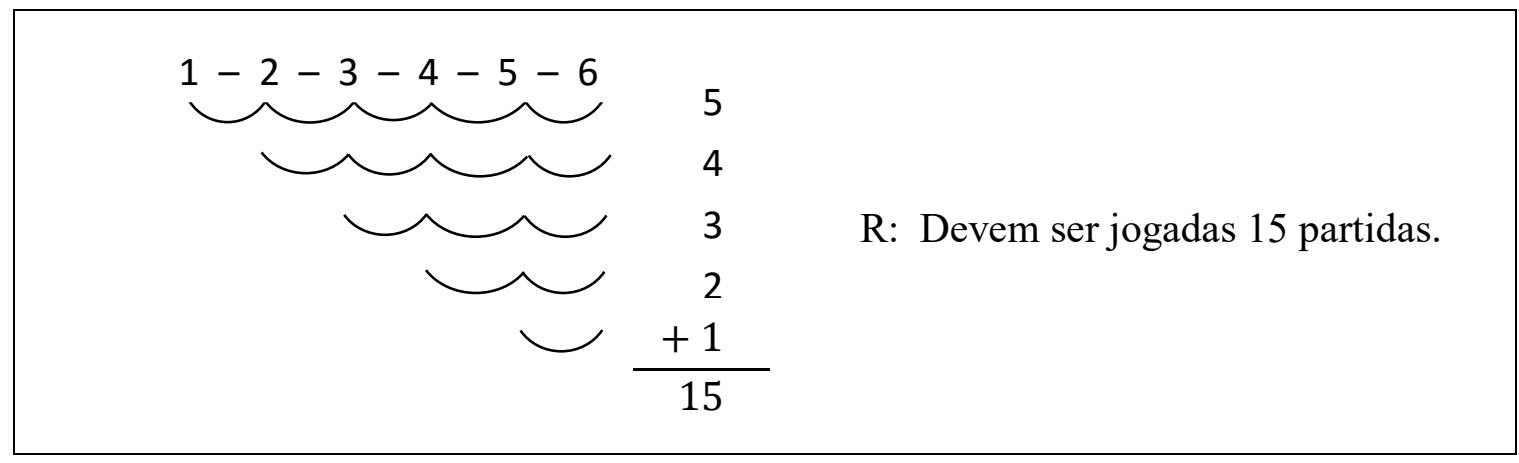

Fonte: Leblanc, Proudfit e Putt (1997).

Depois de colocada essa estratégia na lousa, a qual denominamos de "diagrama”, L1 e L2 disseram que a estratégia estava errada, pensando que haveria repetição de duplas de times. No entanto, mudaram de ideia, conforme pode ser verificado a seguir:

L2: Não vai sair do 1 para o 2, do 2 para o três e sim do 1 para o 2, do 1 para o 3 e assim por diante. Aí depois do 2 para o 3, do 2 para o 4, do 2 para o 5 .

L1: Isso! Eu entendi agora que o aluno tava fazendo. Ele tava indo do 1 para o 2, para o 3, para o 4. E depois do 2 para o 3, para o 4. É só o jeito dele desenhar.

No entanto, esse “jeito de o aluno desenhar" parece que não seria levado em consideração pelo participante L3.

L3: Se ele tivesse colocado 15 eu iria considerar certo. Se estivesse 14 eu daria errado, porque pra mim não tem como eu olhar o desenvolvimento matemático dele.

Pesquisador: Mas você tem que conversar com ele.

L3: Mas daí são outros quinhentos.

Diante desses resultados, entendemos que no trabalho baseado na resolução de problemas, o foco da aprendizagem deve ser o processo e não somente a resposta que os alunos encontram (POZO; ANGÓN, 1998). Desse modo, é necessário realizar uma discussão com eles sobre as estratégias que utilizaram, levando-os a se envolver na etapa de monitoramento do processo de resolução para que possam, assim, avaliar a racionalidade da resposta encontrada (BRITO, 2006).

Para encerrar a discussão do uso de estratégias dessa situação de Matemática, apresentamos a resolução por meio da fórmula de Combinação Simples, conforme Figura 4. Foi possível enfatizar que, apesar de a situação de Matemática analisada ser muitas vezes utilizada como aplicação do conteúdo/fórmula da Combinação Simples, nota-se que abordá-la na perspectiva da resolução de problemas, considerando-a como ponto de partida, favorece a articulação a outros conteúdos de Matemática como no caso da estratégia apresentada do cálculo do número de diagonais de polígonos regulares. Desse modo, em sala de aula, deve-se permitir aos alunos que tentem, primeiro, resolvê-la por seus próprios meios. 
Figura 4 - Estratégia baseada na fórmula do conteúdo de Combinação Simples

$$
C_{n, p}=\frac{n !}{p !(n-p) !} \rightarrow C_{6,2}=\frac{6 !}{2 !(6-2) !}=\frac{720}{2.24}=15
$$

Fonte: Elaborada pelo autor.

Tendo em vista a discussão sobre o uso direto dessa fórmula no ensino, o diálogo a seguir mostra uma possível síntese dos participantes sobre a ideia de introduzir um conteúdo/conceito de Matemática por meio de um problema: ensinar via resolução de problemas (SCHROEDER; LESTER, 1989).

L1: No começo da aula eu posso dar esse mesmo problema... explico, analiso a estratégia do aluno e depois digo que dá pra resolver de outro jeito, que é... aquele mesmo problema eu consigo resolver pela fórmula?

Pesquisador: Isso. O aluno ou vai conseguir fazer ou não vai conseguir. Isso vai acontecer. Pode ser que ele não consiga de nenhum jeito. Aí você pode incentivar a resolver, por exemplo, assim (diagrama) e pedir que os alunos deem palpites.

L3: A intenção é introduzir um conceito com um problema.

Pesquisador: Aí você destaca que foi feito dessa forma e dessa outra (apontando em lousa as estratégias) e que tem outro jeito que é esse com a expressão. Você pode dizer que se trata de Análise Combinatória e depois introduzir e discutir o conteúdo específico.

L2: Não consigo pensar em um monte de problemas para cada conteúdo que eu vou dar.

L1: Você procura (dizendo para L2) ((risos))

L4: Inventa. ((risos))

Pesquisador: Você pode verificar o que os alunos já aprenderam e o que eles podem utilizar nas estratégias.

O entendimento do ensino via resolução de problemas foi favorecido na pesquisa de Costa e Allevato (2012), a qual, por meio de uma proposta de formação, mostrou que futuros professores de Matemática puderam compreender que o ensino que adota o problema como ponto de partida ajuda a aprender Matemática e que não serviria apenas para aplicá-la. Tal compreensão foi possível porque esses estudantes vivenciaram a busca de possibilidades de resolução e construção do conceito de proporcionalidade via um problema de Geometria, envolvendo o Teorema de Tales.

Ao final dos diálogos, o participante L3 relatou sua compreensão sobre o trabalho, envolvendo as estratégias de resolução de problemas na escola básica.

Eu acho que a escola de maneira geral, desde a quinta-série [sexto ano do Ensino Fundamental] até o terceiro colegial [terceiro ano do Ensino Médio], não tem ensinado estratégias, entende? Tem que ser! Para o aluno ter condições de tudo que ele aprendeu de matemática ser usado como estratégia para ele resolver qualquer problema de matemática ou na vida dele. Quando ele chegar no terceiro colegial, ele ter uma gama de conhecimento matemático grande. E todos esses conhecimentos são estratégias que ele veio aprendendo e desenvolvendo e... mais maduro com relação ao... ser um problema ou um exercício. 
Pesquisas como a de Azevedo (2014) buscaram favorecer justamente a compreensão do ensino via resolução de problemas a futuros professores de Matemática. Essa autora desenvolveu uma formação em que o problema foi abordado como ponto de partida, sendo que a apresentação e discussão das estratégias de resolução proporcionou-lhes o entendimento sobre a possibilidade de se gerar, em sala de aula, um ambiente de troca de ideias e do favorecimento da compreensão de Matemática.

\section{Considerações finais}

Nosso objetivo foi o de investigar a compreensão de quatro futuros professores sobre resolução de problemas no ensino de Matemática por meio da abordagem do problema como ponto de partida. Buscamos favorecer tal compreensão por meio de uma proposta de formação, baseada na discussão de aspectos teóricos da resolução de problemas e nas possíveis estratégias de resolução.

Verificamos que as estratégias mais utilizadas envolveram o uso de uma equação, de forma isolada ou associada a uma figura ou tabela. A estratégia de montagem de uma tabela para se enumerar os valores e, assim, obter a(s) resposta(s) foi entendida como coerente pelos participantes e útil à resolução. O caso da estratégia de construção de uma tabela para ajudar a encontrar um padrão (fórmula matemática) foi uma forma nova de resolução, mas os futuros professores sentiram dificuldades no seu uso e até mesmo na sua condução em sala de aula na escola.

Do ponto de vista da formação do professor que ensina Matemática, é importante conhecer os vários tipos de estratégias de resolução e ter a compreensão daquelas que os alunos da escola precisarão de direcionamento ou condução à aprendizagem. Nessa formação, verificamos ainda que os participantes da pesquisas precisam desenvolver conhecimentos que envolvem o uso de régua e compasso na construção de conceitos geométricos para conseguirem resolver problemas dessa natureza, bem como desenvolver conhecimentos conceituais de geometria.

Por meio da situação de Matemática que analisamos neste estudo, foi possível verificar que os participantes já conseguiam pensar sobre possíveis estratégias de resolução, pois o participante L4 utilizou as estratégias "tabela/quadro" e "diagrama de flechas". Já o participante L1 utilizou-se de uma figura articulada à fórmula das diagonais de polígonos e da fórmula da Combinação Simples.

Consideramos a estratégia do cálculo do número de diagonais de polígonos convexos um exemplo importante para ser discutido com os alunos em sala de aula na resolução de situações de Matemática que assim a permitam, uma vez não bastaria apenas aplicar a fórmula para obter o número de diagonais, mas, sobretudo, realizar uma compreensão adequada do problema. Tal compreensão implicaria na apresentação de uma resposta coerente que, no caso da situação de 
Matemática de nosso estudo, deve levar em consideração a necessidade de se adicionar o número de diagonais ao número de lados.

Além disso, a discussão da estratégia de um aluno para resolver essa situação de Matemática ajudou a mostrar aos participantes a necessidade de se valorizar os conhecimentos trazidos pelos alunos da escola às resoluções. Assim, ao finalizarmos a discussão com a apresentação da forma matemática de resolução (cálculo da Combinação Simples), os participantes já conseguiam perceber a necessidade de valorizar as estratégias dos alunos da escola quando se aborda o problema como ponto de partida no ensino de um conteúdo.

Contudo, os futuros professores puderam perceber a importância de se levar em consideração o trabalho em sala de aula que valorize as estratégias dos alunos. Pode-se inferir que no curso sobre resolução de problemas foi possível desenvolver-lhes a compreensão a respeito da condução do ensino-aprendizagem da Matemática via resolução de problemas. Devido à vivência que lhes foi proporcionada, pudemos favorecer-lhes, sobretudo, a compreensão sobre a condução de aulas de Matemática nas quais o problema é o ponto de partida, tendo em vista as quatro ações no ensino propostas por Proença (2015).

A nossa pesquisa, assim como os estudos de Nunes (2010), Costa e Allevato (2012), Azevedo (2014) e Proença (2015), teve a preocupação em favorecer a futuros professores que ensinam (ensinarão) Matemática a condução de aulas baseadas no ensino que adota o problema como ponto de partida. De modo específico, nossa pesquisa evidencia a importância do professor em elencar/prever as possíveis estratégias de resolução de determinada situação de Matemática que vai ser utilizada como ponto de partida no ensino. Isso implica no aspecto de que não basta apenas conhecer sobre resolução de problemas como abordagem de ensino, mas também em se ter domínio/conhecimento da Matemática que pode ser utilizada.

\section{Referências}

AZEVEDO, E. Q. O processo de ensino-aprendizagem-avaliação de matemática através da resolução de problemas no contexto da formação inicial do professor de matemática. 2014. 268f. Tese (Doutorado em Educação Matemática) - Instituto de Geociências e Ciências Exatas, UNESP, Rio Claro.

BITTAR, M.; FREITAS, J. L. M. Fundamentos e metodologia de matemática para os ciclos iniciais de ensino fundamental. 2. ed. Campo Grande-MS: UFMS, 2005.

BOGDAN, R.; BIKLEN, S. Investigação Qualitativa em Educação. Uma introdução à teoria e aos métodos. Trad. Maria João Alvarez; Sara Bahia dos Santos e Telmo Mourinho Baptista. Porto: Porto, Coleção Ciências da Educação. 1994.

BRASIL. Ministério da Educação. Parecer CNE/CP 9/2001. Diretrizes Curriculares Nacionais para a Formação de Professores da Educação Básica, em nível superior, curso de licenciatura, de 
graduação plena. Diário Oficial da União, Brasília, de 18 jan. 2002. Seção 1, p. 31. Disponível em <http://portal.mec.gov.br/cne/arquivos/pdf/009.pdf> Acesso em 09 abril 2015.

BRASIL. Secretaria de ensino fundamental. Parâmetros Curriculares Nacionais. $3^{\circ}$ e $4^{\circ}$ Ciclos. Brasília: SEF/MEC, 1998.

BRITO, M. R. F. Alguns aspectos teóricos e conceituais da solução de problemas matemáticos. In: BRITO, M. R. F. (Org.). Solução de problemas e a matemática escolar. Campinas: Alínea, 2006, p. 13-53.

CAI, J.; LESTER, F. Por que o ensino com resolução de problemas é importante para a aprendizagem do aluno? Boletim GEPEM, n. 60, jan./jun., 147-162, 2012.

CHARLES, R. I. The role of problem solving. Arithmetic teacher, 32, p. 48-50, february, 1985.

CHI, M. T. H.; GLASER, R. A capacidade para a solução de problemas. In: STERNBERG, R. As capacidades intelectuais humanas: uma abordagem em processamento de informações. Trad. Dayse Batista. Porto Alegre: Artes Médicas, 1992, p. 249-275.

COSTA, M. S.; ALLEVATO, N. S. G. Futuros professores de matemática e o ensino de proporcionalidade através da resolução de problemas de geometria. Boletim GEPEM, n. 61, jul./dez., p. 109-123, 2012.

FI, C. D.; DEGNER, K. M. Teaching through problem solving. Mathematics Teacher, v.105, n. 6, february, p. 455-459, 2012.

KANTOWSKI, M. G. Algumas considerações sobre o ensino para a resolução de problemas. In: KRULIK, S.; REYS, R. E. (Org.) A resolução de problemas na matemática escolar. Trad. Hygino H. Domingues e Olga Corbo. São Paulo: Atual, 1997, 343p., p. 270-282.

KRULIK, S.; RUDNICK, J. A. Teaching problem solving to preservice teachers. Arithmetic Teacher, v. 29, n. 6, p. 42-45, february, 1982.

LEBLANC, J. F.; PROUDFIT, L.; PUTT, I. J. Ensinando resolução de problemas na elementary school. In: KRULIK, S.; REYS, R. E. (Org.) A resolução de problemas na matemática escolar. Trad. Hygino H. Domingues e Olga Corbo. São Paulo: Atual, 1997, p. 148-164.

LEITE, A. S. et al. Análise de Erros: percepções e significados. In: ENCONTRO DE MATEMÁTICA, 2., 2012. Caetité-Bahia. Anais... Caetité: SBEM, 2012.

NUNES, C. B. O Processo Ensino-Aprendizagem-Avaliação de Geometria através da Resolução de Problemas: perspectivas didático-matemáticas na formação inicial de professores de matemática. 2010. 430p. Tese (Doutorado em Educação Matemática) - Instituto de Geociências e Ciências Exatas, UNESP, Rio Claro.

PIROLA. N. A. et al. Resolução de problemas com informações supérfluas: uma análise do desempenho de alunos sob a ótica da teoria de Krutetskii. In: SEMINÁRIO INTERNACIONAL DE PESQUISA EM EDUCAÇÃO MATEMÁTICA, 3., 2006, Águas de Lindóia. Anais... Águas de Lindóia: SBEM, 2006. CD-ROM.

POZO, J. I; ANGÓN, Y. M. A solução de problemas como conteúdo procedimental da educação básica. In: POZO, J. I. (Org.). A solução de problemas: aprender a resolver, resolver para aprender. Porto Alegre: ArtMed, 1998, p. 139-165.

PROENÇA, M. C. O ensino de frações via resolução de problemas na formação de futuras professoras de pedagogia. Bolema, Rio Claro, v. 29, n. 52, ago., p.729-755, 2015.

. O ensino por meio da resolução de problemas: conhecimentos e perspectivas de professores de matemática do PDE. In: ENCONTRO PARANAENSE DE EDUCAÇÃO MATEMÁTICA, 12., 2014. Campo Mourão-PR. Anais... Campo Mourão-PR: EPREM, 2014. 
Os conhecimentos de licenciandos em matemática sobre a resolução de problemas. In: CONGRESO IBEROAMERICANO DE EDUCACIÓN MATEMÁTICA, 7., 2013. MontevidéuUruguai. Anais... Montevidéu, VII CIBEM, 2013.

REDLING, J. P. A metodologia de resolução de problemas: concepções e práticas pedagógicas de professores do ensino fundamental. 2011. 166p. Dissertação (Mestrado em Ensino de Ciências e Matemática) - Faculdade de Ciências, UNESP, Bauru.

SCHROEDER, T. L.; LESTER, F. K., JR. Developing understanding in mathematics via problem solving. In: TRAFTON, P. R.; SHULTE, A. P. (Eds.). New directions for elementary school mathematics. Reston: NCTM, 1989, p. 31-42.

SHULMAN, L. S. Those who understand: knowledge growth in teaching. Educational Researcher, v. 15, n. 2, february, p. 04-14, 1986.

SOUZA, A. C. P. Análise Combinatória no Ensino Médio apoiada na Metodologia de EnsinoAprendizagem-Avaliação da Matemática através da Resolução de Problemas. 2010. 343f. Dissertação (Mestrado em Educação Matemática) - Instituto de Geociências e Ciências Exatas, UNESP, Rio Claro.

Submetido em outubro de 2015 Aprovado em abril de 2016 